lish, French or German, of "papers concerning all aspects of photochemistry and photobiology but will be primarily concerned with articles of an analytical nature dealing with the photochemistry of organic substances and the action of infra-red, visible and ultra-violet light on biological systems". Papers dealing with ionizing radiations are specifically excluded. Members of the editorial board are Dr. E. J. Bowen, University of Oxford; Prof. S. Claesson, Institute for Physical Chemistry, Uppsala; Dr. A. Hollaender, Oak Ridge National Laboratory, United States; Prof. A. O. McLaren (executive editor), University of California; and Prof. D. Shugar, Institute of Biochemistry and Biophysics, Warsaw. These are supported by an international group of leading workers forming an editorial advisory board of thirty-three. Although duplicating, to some extent, the aims of Radiation Research, the institution of a separate journal devoted to the physical, chemical and biological aspects of non-ionizing radiations seems justifiable at the present time. The contents of the first issue (mainly concerned with nucleic acids and related substances) show a high standard of editorial policy; in particular, citations of recent literature in the field-as a regular feature-should be of great value to research workers involved.

\section{Large-Scale Mach-Zehnder Interferometer}

THE new large-scale Mach-Zehnder interferometer recently announced by the Carl-Zeiss Foundation of Oberkochen, Western Germany, is a further development of the well-known single-mirror focusing model, and incorporates optical systems and focusing mechanisms of very high standard. The total deviation from parallelism and straightness in the interference fringes is less than one-tenth of a fringe width throughout, even though the light beam is reflected four times and passes through two glass plates before the measurements are made. The need for two cameras has been obviated. By shortening the focal length of the objective it has been possible to unite the cameras and, whereas previously the former intermediate image was barely $1 \mathrm{~cm}$. in diameter, it is now of a size to be directly photographed. The interference image is very bright and the exposure time required for a photographic record is extremely short. By means of a large $13 \times 18 \mathrm{~cm}$. ground-glass screen it is possible for the interference fringes to be viewed simultaneously by several viewers. The agents in the United Kingdom are Degenhardt and Co., Ltd., 6 Cavendish Square, London, W.1, from whom a coloured illustrated booklet can be obtained in which is given full details of the interferometer, associated camera and other accessories for various applications in the fields of aerodynamics, fluid dynamics, thermodynamics and ballistics.

\section{Solvents in Dry Cleaning}

Risks of fire and explosion from the use of solvents in dry cleaning processes, and the precautions that should be taken to reduce such hazards, are discussed in Dry Cleaning Plant: Precautions Against Solvent Risks, a booklet in the Safety, Health and Welfare, New Series, published by the Ministry of Labour (No. 15. Pp. 20. London: H.M.S.O. 1s. 3d. net). Solvents in general use are divided into two categories-fiammable and non-flammable. The former are white spirit and petroleum distillate, and the latter mainly chlorinated hydrocarbons, such as trichloroethylene and perchloroethylene. When dry cleaning was first introduced, highly flammable solvents such as benzine or petrol were used. Fires and explosions causing serious injury and damage resulted. The introduction, in 1949 , of the Dry Cleaning Regulations, which restricted the use of petrol and other liquids with a flash-point below $90^{\circ} \mathrm{F}$., has greatly reduced risks from fire and explosions in the washing and hydro-extraction stages. There is still a risk of serious fires and explosions in tumblers used for drying articles cleaned in white spirit or petroleum distillate. Flammable solvents now being used have a flash-point of about $100^{\circ} \mathrm{F}$. At atmospheric temperatures these do not give off vapour in concentrations high enough to form flammable or explosive mixtures. In some processes, such as tumbling, temperatures of about $150^{\circ} \mathrm{F}$. are usual, giving rise to explosive concentrations of solvent vapours unless adequate precautions are taken.

\section{Hydrology in Great Britain}

BECAUSE of the ever-increasing demand for water there is increasing need for information about the quantity and quality of supplies available. Data on the flow of many rivers in Britain are given annually in The Surface Water Year-Book of Great Britain, issued by the Ministry of Housing and Local Government and the Scottish Office. In the latest issue. that for 1959-60, for the first time graphs are given which show, for selected stations, the frequency of discharges above given values (Hydrometric Statistics for British Rivers, together with Related Rainfalls, for the year ended 30th September, 1960. Pp. xiv + 113 (2 maps). London: H.M.S.O., 1961. 22s. 6d. net). Information of a different kind is collected in the Selected Bibliography of Hydrology, prepared on behalf of the International Association of Scientific Hydrology of the International Union of Geodesy and Geophysics by the Hydrology Sub-Committee of the British National Committee for Geodesy and Geophysics (Selected Bibliography of Hydrology (with abstracts), United Kingdom, for the years 1955-59 inclusive. Pp. 52. London: The Royal Society, 1961). This contains references, with brief abstracts, of publications which appeared between 1955 and 1959 on many aspects of hydrology of both surface and ground waters. References to overseas work are included if it has been published in the United Kingdom. It is hoped that further bibliographies, dealing with later years, will be published periodically.

\section{Geological Atlas of British Guiana}

FEw regions in the world are more inhospitable to the geological surveyor than is British Guiana. Throughout about nine-tenths of the country access is greatly hindered by swamps and forest; and over much of the remainder exposures are scanty, the bedrock being hidden by deep tropical weathering and by Tertiary to Quaternary sands and clays. But despite these adverse field conditions, the postwar years have seen a great expansion in the work of the local Geological Survey, financed largely by Colonial Development and Welfare grants from the British Government; and there is now a staff of fifteen field geologists engaged in exploration, aided by a team of specialists centred in Georgetown. In 1957 a new programme of geological mapping was initiated, with the objective of covering the whole of British Guiana in seven years; and from this effort there has recently resulted a new series of blackand-white geological maps on a scale of $1: 200,000$, each sheet covering one-quarter of a degree square 